

ISSN Eletrônico 2175-6600

Vol. 12 | Número Especial | 2020

Rita de Cássia Prazeres Frangella

(9) iD

Universidade do Estado do Rio de Janeiro (UERJ) rcfrangella@gmail.com

\section{AVALIAÇÃO COMO SIGNO DE QUALIDADE: PROBLEMATIZANDO AS (IN)DEFINIÇÕES NAS PRODUÇÕES CURRICULARES}

\section{RESUMO}

$\bigcirc$ artigo objetiva pôr em discussão o uso de índices de avaliação tomados como indicadores de qualidade e articulados como justificativa para produção de políticas curriculares. Intenta-se problematizar os usos discursivos desses índices como definidores de qualidade. Para tanto, recorre-se à leitura de diferentes políticas educacionais em suas inferências sobre avaliação. Argumenta-se, a partir de uma perspectiva discursiva pós-estrutural e de leitura desconstrutiva da ideia de avaliação como signo que essa remete àqualidade como verdade fixando sentidos de avaliação e, de forma articulada, também de currículo como univocidade e totalização. Defende-se que a avaliação, na passagem entre o constatativo e performático, deve emergir como acontecimento, em diálogo com Derrida e Bhabha.

Palavras-chave: Políticas curriculares. Avaliação. Discurso.

\section{EVALUATION AS A SIGN OF QUALITY: PROBLEMATIZING THE (IN) DEFINITIONS IN CURRICULAR PRODUCTIONS}

\begin{abstract}
The article aims to discuss the use of evaluation indexes taken as quality indicators and articulated as a justification for the production of curricular policies. It is intended to problematize the discursive uses of these indexes as defining quality. For this purpose, different educational policies are used in their inferences about evaluation. It argues, from a post-structural discursive perspective and from a deconstructive reading of the idea of evaluation as a sign that it refers to quality as truth, establishing meanings of evaluation and, in an articulated way, also of curriculum as univocity and totalization. It is argued that the evaluation should emerge as an event, in dialogue with Derrida and Bhabha.
\end{abstract}

Keywords: Curriculum policies. Evaluation. Discourse.

Submetido em: 15/04/2020

Aceito em: 13/06/2020

Publicado em: 10/12/2020

do) http://dx.doi.org//0.28998/2 175-6600.2020v12nEspp558-57| 


\section{INTRODUÇÃO}

A busca pela qualidade na educação é força motriz de tantos movimentos que hoje acompanhamos e que delineiam as ações políticas no campo educacional, figurando como objetivo e, ao mesmo tempo, justificativa para essas ações. Diferentes demandas, sob a égide da qualidade, mobilizam e disputam significações e projetos para a educação. Uma das questões que tem se evidenciado nessa discussão é a tomada da avaliação como signo de qualidade.

Para tanto, nesse texto, põe-se em discussão o uso de índices de avaliação tomados de forma direta como indicadores de qualidade sendo ao mesmo tempo articulados como justificativa para produção de políticas curriculares. Para além de uma discussão simplista nos termos de concordância ou refutação dos indicadores produzidos a partir das avaliações, o que se problematiza são os usos discursivos para marcar processos sociais (BHABHA, 20I I), da tomada desses como marco definidor de qualidade. Nessa linha argumentativa, faz-se necessário discutir também a compreensão de qual concepção de avaliação se desdobra dessa dinâmica, o que não se dá dissociado de concepções curriculares. Assim, defende-se também um imbricamento das políticas de avaliação com políticas curriculares, não como fenômenos sociais pareados, mas que se constituem mutuamente.

Assim, o objetivo principal dessa reflexão é a análise da avaliação como signo de qualidade, problematizando a própria ideia de signo, numa perspectiva pós-estrutural, alinhando tal discussão à noção de desconstrução do signo tal como defendida por Derrida (201 I). Para tanto, no desenvolvimento do texto, após uma apresentação da problemática focalizada, discuto a produção de um discurso de atrelamento avaliação-qualidade e como esse se espraia e baliza políticas curriculares contemporâneos, o que se evidencia na leitura exploratória de diferentes políticas como é possível observar nos trechos postos em destaque: a convergência da qualidade como dada pela avaliação, o que vai desdobrando-se no que refiro-me como avaliação como signo qualidade - é a partir dessa relação estabelecida com a noção de signo que opero a partir das formulações de Derrida, numa leitura desconstrutiva do signo, abalando ideias como verdade, realidade e presença, o que permite, em associação, problematizar o sentido de avaliação como afirmação da presença e veracidade da qualidade.

Sem pretender invalidar quaisquer avaliação/índice desenvolvido -SAEB, IDEB, Prova Brasil, ENEM, Avaliação Nacional da Alfabetização/ANA ${ }^{1}$, entre outras- o que incidiria na redução da discussão a uma lógica binária, num isto ou aquilo que, com Bhabha (200 I), venho compreendendo como ação infrutífera: investir em polaridades contrastantes, contrai o espaço intersticial potente de produções híbridas

\footnotetext{
I Aqui ponho em destaque, citando-as, avaliações que integram a Política Nacional de Avaliação (20 I 8) e se relacionam com o SAEB (Sistema de Avaliação da Educação Básica). Contudo, essas não totalizam as políticas de avaliação no país; há que se considerar as políticas propostas por diferentes esferas (estaduais e municipais) que também participam desse contexto avaliativo. Entretanto não é objetivo desse estudo voltar-se para a análise de uma política de avaliação em sua especificidade.
} 
- chama atenção a centralidade dessas avaliações na discussão de políticas públicas como expressão de qualidade, numa operação discursiva que objetifica sentidos de qualidade, conferindo às avaliações a ideia de transparência e representação da realidade, o que se pode observar no que é estabelecido na Política Nacional de Avaliação e Exames da Educação Básica (BRASIL, 20।8, p. I):

\footnotetext{
Art. $2^{\circ}$ São objetivos da Política Nacional de Avaliação e Exames da Educação Básica:

I - diagnosticar as condições de oferta da educação básica;

II - verificar a qualidade da educação básica;

III - oferecer subsídios para o monitoramento e o aprimoramento das políticas educacionais;

IV - aferir as competências e as habilidades dos estudantes;

$\checkmark$ - fomentar a inclusão educacional de jovens e adultos; e

$\mathrm{VI}$ - promover a progressão do sistema de ensino

Art. $3^{\circ}$ São princípios da Política Nacional de Avaliação e Exames da Educação Básica:

I - igualdade de condições para o acesso e a permanência do estudante na escola;

II - garantia do padrão de qualidade; e

III - garantia do direito à educação e à aprendizagem ao longo da vida.
}

Não se trata de uma política de avaliação apenas, mas o atrelamento avaliação-exame e o indicativo do exame como expressão de qualidade, o que remete à linha de problematização aqui proposta. Argumento que tais avaliações não devem e não podem ser consideradas como indicadores de qualidade, sob pena de uma essencialização que, ao estabelecer uma correspondência biunívoca de qualidade à desempenho, busca fixar uma perspectiva em que qualidade significa proficiência e eficácia. Dessa forma, a partir do entendimento da política curricular como processo discursivo, amparada nos estudos de Derrida (2004, 20 I I) e Bhabha (200 I , 20 I I), intento pôr em suspensão o par binário avaliação-qualidade, como possibilidade de reativação de outros sentidos possíveis na luta pela significação da escola, do currículo, da educação.

\section{DUALIDADE FIXADA: AVALIAÇÃO/QUALIDADE}

As ações no campo das políticas educacionais contemporâneas tem se voltado para o investimento no delineamento de políticas curriculares para os diferentes níveis da educação básica e formação de professores, num movimento que tem como premissa que prescrições curriculares podem renovar/alterar o panorama educacional respondendo às demandas de qualidade, essas se apresentam como justificativas que mobilizam esses arranjos e exigem que tais propostas se desenvolvam como instrumentos de superação da crise vivida na educação. Nesse sentido, observar as articulações em torno de uma discurso de crise e como esses incitam movimentos discursivos que colocam de forma alinhada currículo-avaliação e essa última, então como estratégia de controle e garantia da qualidade permite compreender a dualidade avaliação/qualidade. E isso é possível inferir na leitura dessas políticas, observando como esses sentidos de avaliação e qualidade são mobilizados, o que se faz nessa seção. 
O discurso de crise é um mobilizador potente no encadeamento de processos de significação para a educação, principalmente na relação estabelecida com a ideia de qualidade. Nesse alinhamento discursivo indica-se que há crise e essa é uma crise de qualidade. Se o acesso a educação foi um problema que se apresentava como entrave no cenário educacional brasileiro, mas que tem avançado continuamente $($ IBGE, 20|9)2 a qualidade da educação ou falta dela coloca-se como questão e fomenta o discurso de crise. Macedo (2013, p. 445) sobre a noção de crise afirma :

a ideia de crise vem desempenhando como exterior constitutivo de discursos concretos que fixam sentidos para currículo, a maioria deles articulados em torno de significantes como qualidade. A crise é o inimigo que se exterioriza de modo a garantir a força de um determinado discurso sobre currículo e legitimar a exclusão de outras significações.

A retórica da crise movimenta argumentos que vão, na linha do que Laval (2017) defende, imprimindo modos de governo que alimentam uma defesa de que mudanças são necessárias para estancar a crise. Nesse sentido, de forma ambivalente, exige e justifica uma série de iniciativas de tom reformista que, a partir de uma lógica normativa, possa assegurar que a crise seja superada. Exerce uma força centrípeta que justifica também que essa investida na melhoria dos processos atingidos pela crise que demandariam então maior controle de forma a torná-los eficazes e eficientes. E aí que, em função desse binômio, há outro alinhamento discursivo que participa da produção da significação de qualidade e que também é mobilizado na resposta à crise evidenciada na educação: a avaliação. Nesse encadeamento, a avaliação é vista como signo de qualidade, daí que o incremento de políticas de avaliação são vistas como ações que incidem sobre a melhoria e qualificação da oferta educacional e, na esteira disso, de políticas curriculares. Nesse sentido, a centralidade da avaliação permite inferir o que já argumentei como se constituindo uma dimensão instituinte de políticas curriculares (FRANGELLA e MENDES, 20I8). Um encadeamento discursivo em que eficácia-eficiência-qualidade-avaliação impele na redução da avaliação como resultado, e para suplantar a crise, trata-se da busca do bom resultado. E o que é o bom resultado? Trata-se, nessa linha, do resultado visível nos exames, das performances mensuráveis como garantia de qualidade "numa clara mudança de paradigma para uma cultura gerencial, que adota a política de avaliação como elemento central, caracterizando, desde então, a avaliação como marco regulatório para as reformas educacionais e as políticas públicas em curso no país" (FRANGELA; MENDES, 2018, p.302).

Uma leitura exploratória de diferentes políticas curriculares contemporâneas evidenciam como as avaliações são enunciadas como justificativas para sua proposição ou como elementos estruturantes dessas. Na Base Nacional Comum Curricular/BNCC (Brasil, 20 I8) justifica-se o alinhamento de uma concepção

\footnotetext{
${ }^{2}$ Informações disponíveis em Pesquisa Nacional por Amostra de Domicílios Contínua: Educação:20 I 8. IBGE, 20 I9. Os dados apresentados indicam que: "No Brasil, em 2018, 56,4 milhões de pessoas frequentavam escola ou creche. Entre as crianças de 0 a 3 anos, a taxa de escolarização foi 34,2\%, o equivalente a 3,5 milhões de estudantes. [...]Entre as crianças de 4 e 5 anos, faixa correspondente à pré-escola, a taxa foi 92,4\% em 2018 [...].já na faixa de idade de 6 a 14 anos, a universalização, desde 2016, já estava praticamente alcançada, com 99,3\% das pessoas na escola em 20 I8. A taxa de escolarização entre os jovens de 15 a 17 anos, em 2018, foi de 88,2\%."(IBGE, 2019, p. 4)
} 
curricular baseada em competências às demandas produzidas por avaliações internacionais, que também

baseiam-se na noção de competência:

Além disso, desde as décadas finais do século $X X$ e ao longo desteinício do século $X X \mid$, o foco no desenvolvimento de competências tem orientado a maioria dos Estados e Municípios brasileiros e diferentes países na construção de seus currículos. É esse também o enfoque adotado nas avaliações internacionais da Organização para a Cooperação e Desenvolvimento Econômico (OCDE), que coordena o Programa Internacional de Avaliação de Alunos (Pisa, na sigla em inglês) I I, e da Organização das Nações Unidas para a Educação, a Ciência e a Cultura (Unesco, na sigla em inglês), que instituiu o Laboratório Latino-americano de Avaliação da Qualidade da Educação para a América Latina (LLECE, na sigla em espanhol) (BRASIL, 20 I7, p. I3)

No caso do Pacto Nacional para Alfabetização na Idade Certa/PNAIC (Brasil, 20 I 2) o programa foi construído tendo como estrutura a indicação de diferentes eixos articulados. Um deles era o eixo de avaliação que trouxe consigo a instituição da Avaliação Nacional da Avaliação/ANA (que desde a sua criação passou a integrar o SAEB - Sistema de Avaliação da Educação Básica³):

Este eixo reúne três componentes principais: avaliações processuais, debatidas durante o curso de formação, que podem ser desenvolvidas e realizadas continuamente pelo professor junto aos educandos. A segunda mudança refere-se à disponibilização de um sistema informatizado no qual os professores deverão inserir os resultados da Provinha Brasil de cada criança, no início e no final do $2^{\circ}$ ano e que permitirá aos docentes e gestores analisar de forma agregada essas informações e adotar eventuais ajustes. A terceira medida é a aplicação, junto aos alunos concluintes do $3^{\circ}$ ano, de uma avaliação externa universal, pelo INEP, visando aferir o nível de alfabetização alcançado ao final do ciclo, e que possibilitará às redes implementar medidas e políticas corretivas. Também neste caso, o custo dos sistemas e das avaliações externas será assumido pelo Ministério da Educação.

Em 2013, o Ministério da Educação publicará um edital informando os critérios de premiação e reconhecimento aos professores, escolas e redes de ensino que mais avançarem na alfabetização das suas crianças, considerando os resultados aferidos nas avaliações. (BRASIL, 20I3, p.l3 caderno de apresentação do PNAIC)

Na apresentação da Política Nacional de Alfabetização (BRASIL, 2019) expressa-se com clareza como os resultados de avaliações são tomados como referência para sua proposição:

A educação é uma preocupação central das nações do século XXI. Não se pode conceber um futuro próspero para o país que descuida das suas políticas educacionais, uma vez que o progresso científico, econômico e social de um povo está intimamente relacionado com a qualidade da sua educação. No entanto, os resultados obtidos pelo Brasil nas avaliações internacionais e os próprios indicadores nacionais revelam um grave problema no ensino e na aprendizagem de leitura, de escrita e de matemática. É uma realidade que precisa ser mudada. Por isso a Política Nacional de Alfabetização pretende oferecer às redes e aos alunos brasileiros, por meio de programas e ações, a valiosa contribuição das ciências cognitivas, especialmente da ciência cognitiva da leitura. Uma política de alfabetização eficaz terá reflexos positivos não apenas na educação básica, mas em todo o sistema educacional do país. (Seção: Nota do ministro)

3 O Sistema de Avaliação da Educação Básica (Saeb) é um conjunto de avaliações externas em larga escala que permite ao Inep realizar um diagnóstico da educação básica brasileira e de fatores que podem interferir no desempenho do estudante. Acerca do SAEB vale destacar que sua criação se deu em 1990 e só em 20l I foi criado o IDEB - índice de desenvolvimento da Educação básica composto pelas médias de desempenho dos estudantes, apuradas no Saeb, juntamente com as taxas de aprovação, reprovação e abandono, apuradas no Censo Escolar. Ver: http://portal.inep.gov.br/web/guest/educacao-basica/saeb 
O parecer 22/2019 do Conselho Nacional de Educação sobre a Base Nacional Curricular Formação, no relatório que fundamenta e justifica o projeto de resolução aprovado, há o item I .2 intitulado "Indicadores de aprendizagem e da formação de professores: o desafio do baixo valor social da carreira do magistério no Brasil”. Nessa seção afirma-se:

Apesar do esforço nacional das três instâncias educacionais federativas e da sociedade civil vinculada à área da educação, o desafio da aprendizagem na idade adequada a cada etapa escolar ainda persiste, a começar pela alfabetização das crianças brasileiras, quando se toma como referência os resultados da Avaliação Nacional de Alfabetização (ANA) de 2016 do Ministério da Educação. No Brasil, a porcentagem de estudantes do 30 ano do Ensino Fundamental (EF), com o nível suficiente de alfabetização, proficientes em Leitura, Escrita e Matemática é de apenas 45,3\%, 66,2\% e 45,5\%, respectivamente. Considerando a proficiência dos estudantes do $5^{\circ} \mathrm{e}$ do $9^{\circ}$ ano do Ensino Fundamental (EF) e do $3^{\circ}$ ano do Ensino Médio (EM) em Língua Portuguesa e Matemática, tendo como referencial os resultados do Sistema de Avaliação da Educação Básica (Saeb), no período de 2007 a 20 I5, verifica-se que o país avançou substancialmente no $5^{\circ}$ ano, alcançando discreto aumento no $9^{\circ}$ ano, mas encontra-se sem avanço, com tendência de queda, no $3^{\circ}$ ano do Ensino Médio, como se pode constatar na Tabela I. [...]

Nos anos iniciais do Ensino Fundamental, o país vem atingindo melhores indicadores do ldeb e aproximando-se da meta projetada; para os anos finais do Ensino Fundamental, o Ideb melhorou ao longo dos dez anos, mas como foi um avanço tímido, o país não alcançou a meta projetada para o Ideb entre 2013 e 2017. Quanto ao Ensino Médio, o Ideb está estacionário, deixando de cumprir a meta projetada a cada dois anos, e se distanciando ainda mais dela. Embora não contemplada no Ideb, a desigualdade de desempenho na Prova Brasil entre grupos sociais, o que tem sido constatado por várias pesquisas acadêmicas, encontra-se em patamares muito altos. Não só a diminuição dessa desigualdade, mas também a melhoria no desempenho desses indicadores, exigem a contribuição dos professores, além do incremento das políticas públicas para a área.

Esses resultados nos levam a pensar em dois aspectos. $O$ primeiro se refere à regulação da formação e do exercício profissional para o magistério, conforme o inciso III do art. 13 da LDB, pelo qual os docentes devem se incumbir de zelar pela aprendizagem dos estudantes. Nesse sentido, a aprendizagem passa a ser a principal incumbência do professor, ou seja, a centralidade do tradicional processo de ensino e de aprendizagem não está mais na atividade meio, ou no simples repasse de informações, mas na atividade fim, que diz respeito ao zelo pela aprendizagem dos estudantes, uma vez que a finalidade primordial das atividades de ensino está nos resultados de aprendizagem. $\mathrm{O}$ art. 23 da LDB preconiza que a forma de organização da Educação Básica deve ser considerada "sempre que 0 interesse do processo de aprendizagem assim o recomendar" (CNE, 2019, p. 4-5 - grifos próprios)

A longa citação justifica-se pelo nexo possível de ser observado que vai se estabelecendo entre resultados, avaliação e qualidade e como esses sentidos articulados vão municiando projetos que atrelam avaliação à melhoria e, ao mesmo tempo, maior controle centralizado. Nesse sentido, a avaliação vai ganhando feições de projetos regidos por uma lógica gerencial, onde funciona como estratégia de monitoramento curricular. Isso pode ser observado à medida em que a leitura de indicadores afasta-se de uma dimensão formativa e que os próprios indicadores se convertem em metas, tornando transparente e objetivo o sentido de qualidade. Como afirma Diaz-Barriga (2003) a avaliação se torna simulacro dos atos educativos, que parecem assim ser orientados para a produção de resultados.

Tal articulação pode ser percebida nos processos propostos para a implementação da BNCC. Isso é perceptível tomando para análise a dimensão 5 que consta das Orientações para implementação proposta pelo MEC (Brasil, 2020): revisão dos projetos pedagógicos. Sobre isso, em materiais indicados 
como orientadores para o desenvolvimento dessa revisão figura a estrutura do projeto pedagógico.

Destaco das orientações dadas dois itens que podemos observar como relacionados:

[...]2. Diagnóstico de indicadores educacionais

- Contempla elementos como: indicadores de acesso (matrícula, evasão); indicadores de fluxo (reprovação, distorção idade-série) e de aprendizagem (resultados da ANA, da Prova Brasil e demais avaliações externas, com análise por componente curricular e por ano, preferencialmente por descritor de

aprendizagem e por turma).

- É importante para: identificar pontos fortes e dificuldades dos alunos e professores e definir prioridades de atuação.

[...]5. Plano de Ação

- Contempla elementos como: os objetivos de aprendizagem dos alunos (a partir dos currículos estaduais de referência); as metas de resultados educacionais (metas para resultados na ANA, Prova Brasil e demais avaliações locais, tanto para aspectos cognitivos como para as competências gerais da BNCC e outros aspectos socioemocionais); materiais didáticos (diretrizes para a escolha e/ou produção autônoma de materiais); os objetivos e métodos para a formação docente dentro da escola (tempos, espaços e metodologias para a formação dentro da escola; papel de cada profissional no processo formativo); formas de avaliação tanto da aprendizagem dos alunos como da formação de professores.

- Esse plano deve ser elaborado à luz do diagnóstico de indicadores educacionais da escola e da sua visão missão e princípios.

- É importante que o plano de ação estabeleça prioridades, para que de fato seja factível no período de tempo de que se dispõe.

- É fundamental que esta parte contemple de forma explícita a maneira como a escola se adaptará para a implementação dos novos currículos alinhados à BNCC em todas as suas esferas: objetivos de aprendizagem, metas, materiais didáticos, formação docente e avaliação.

- É importante para: estabelecer um planejamento claro que oriente a atuação de toda a comunidade escolar, bem como o monitoramento e a correção de rota durante o ano. (Disponível em: http://basenacionalcomum.mec.gov.br/images/implementacao/orientacoes_projeto_pedagogico. pdf. Acesso em mar/2020)

Dos extratos de diferentes políticas curriculares aqui apresentados, o último trecho traz de forma mais clara o alinhamento entre avaliação-produção de indicadores-metas-currículo. Há uma taxionomia do desempenho que se desenha na associação feita. $O$ próprio uso da ideia de produção de indicadores já é substantiva: o termo é utilizado como instrumento de medição e monitoramento para avaliação sobre qualidade do processo, infere sobre desempenho, o que é recorrente em análises gerenciais. Assim, a avaliação se contrai ao assumir função de produção de indicadores de desempenho, alinhando-se a uma perspectiva utilitarista, subsumindo qualidade à desempenho, de forma tal que o indicador de desempenho representa expressão positiva e fidedigna da realidade e sendo assim, a busca por melhoria dos resultados/indicadores revela-se como caminho para avanço na qualidade, o que me permite inferir a noção da avaliação como signo de qualidade.

Nesse sentido, a avaliação parece figurar como indicativo de "presença de qualidade" reduzindo uma análise multidimensional a uma única dimensão, numa mudança de rota dos discursos que vinham sendo construídos acerca da qualidade da educação que, ainda que sejam passíveis de crítica e também remetam a ideia da produção de indicadores, traziam a tona outros sentidos para essa discussão, como se observa na leitura do documento disponibilizado na página do Ministério da Educação/MEC - "Indicadores 
de qualidade na Educação" (Ação Educativa, Unicef, PNUD, INEp-MEC, 2004). Nesse, assim é apresentado a ideia de indicadores de qualidade e o seu processo de produção:

Como todos vivemos num mesmo país, num mesmo tempo histórico, é provável que compartilhemos muitas noções gerais sobre o que é uma escola de qualidade. A maioria das pessoas certamente concorda com o fato de que uma escola boa é aquela em que os alunos aprendem coisas essenciais para sua vida, como ler e escrever, resolver problemas matemáticos, conviver com os colegas, respeitar regras, trabalhar em grupo. Mas quem pode definir bem e dar vida às orientações gerais sobre qualidade na escola, de acordo com os contextos socioculturais locais, é a própria comunidade escolar. Não existe um padrão ou uma receita única para uma escola de qualidade. Qualidade é um conceito dinâmico, reconstruído constantemente. Cada escola tem autonomia para refletir, propor e agir na busca da qualidade da educação. Os Indicadores da Qualidade na Educação foram criados para ajudar a comunidade escolar na avaliação e na melhoria da qualidade da escola. Este é seu objetivo principal. Compreendendo seus pontos fortes e fracos, a escola tem condições de intervir para melhorar sua qualidade de acordo com seus próprios critérios e prioridades. Para tanto, identificamos sete elementos fundamentais - aqui nomeados de dimensões - que devem ser considerados pela escola na reflexão sobre sua qualidade. Para avaliar essas dimensões, foram criados alguns sinalizadores de qualidade de importantes aspectos da realidade escolar: os indicadores. (p.5)

As dimensões indicadas são: ambiente educativo, prática pedagógica, avaliação, gestão escolar democrática, formação e condições de trabalho dos profissionais da escola, ambiente físico escolar e ambiente, permanência e sucesso na escola. Posto dessa forma, a discussão que tal documento enseja chama atenção para a produção de indicadores locais que, mesmo mantendo diálogo com políticas de avaliação externas, afastam-se de uma lógica centralizada e centralizadora, ao deslocar para a escola o processo de avaliação, o que permite alinhar ao que venho defendendo em outros estudos (FRANGELLA; CAMPOS, 2019) da escola como lócus de produção de políticas, essas também de avaliação, como processos de disputa por significação que desestabilizam concepções hegemônicas regidas pelo accountability e com isso abrem "possibilidades de diferimento, de manter o fluxo da significação em seus contingentes momentos de fechamento, mas que, sendo provisórios, não advogam para si a qualidade de resposta única e definitiva." (p.562)

Contudo, a hegemonização de uma lógica de accountability implica numa perspectiva reducionista do próprio entendimento da avaliação, que de multidimensional passa a ser linearmente concebida a partir de standards, moduladas por esses, num intrincado processo discursivo em que a testagem/medição suplanta qualquer outra dimensão.

Em sua associação com ideia de qualidade/alcance de metas e parafraseando a obra de Taubman (2009), a avaliação assim pensada faz da escola espaço em que ensina-se por números, pelos números. 


\section{AVALIAÇÃO COMO SIGNO DE QUALIDADE: UMA LEITURA DESCONSTRUTIVA}

O centro, a ausência de jogo e diferença, não será o outro nome da morte? Aquela que tranquiliza, acalma, mas que também do seu buraco angustia e põe em causa? (Derrida, 201 I , p.430)

Ao desenvolver a discussão aqui posta construindo a ideia de avaliação como signo de qualidade faz necessário problematizar essa ideia no questionamento do próprio conceito de signo, buscando outras significações possíveis para avaliação. Para tanto, faço-o no atrevimento de propor uma leitura desconstrutiva, remetendo a perspectiva derridiana e a discussão que o autor propõe para o signo. Assumo o risco, e ao modo derridiano isso se dá sem garantias, de propor uma leitura descontrutiva, advertindo de início que não a tomo como metodologia nem mesmo como conceito a partir do qual é possível categorizar, o que já incidiria numa apropriação aligeirada/alienada do gesto desconstrutivo derridiano que, longe de destruição, implica em abertura. Nesse sentido seria possível dizer que a perspectiva desconstrutiva opera de forma a questionar sistemas fechados de compreensão que excluem e negam outras formas de pensar o real, fixando também esse real, enclausurado numa metafísica dualista (HADDOCK-LOBO, 2008). O que se objetiva nessa seção, ao operar com o pensamento derridiano, é desestabilizar a fixação da avaliação como qualidade, ou em outro modo de dizer, como verdade da qualidade. Busca-se outros sentidos que possam alimentar outras formas de pensar a avaliação.

Assim, trata-se de pôr em suspensão conceitos dogmáticos, o que o próprio Derrida explica em entrevista concedida a Roudinesco (DERRIDA E ROUDINESCO, 2004):

É verdade, sempre me reconheci, quer se tratasse da vida ou do trabalho do pensamento, na
figura do herdeiro [...] o herdeiro devia sempre responder a uma espécie de dupla injunção, a
uma designação -assignation - contraditória: é primeiro preciso saber e saber reafirmar o que
vem "antes de nós, e que recebemos antes mesmo de escolhê-lo, e nos comportar sob esse
aspecto como sujeito livre. Ora é preciso (e este é preciso está inscrito diretamente na herança
recebida), é preciso fazer de tudo para se apropriar de um passado que sabemos no fundo
permanecer inapropriável, que se trate aliás de memória filosófica, da precedência de uma língua,
de uma cultura ou da filiação em geral. Reafirmar, o que significa? Não apenas aceitar a herança,
mas relançá-la de outra maneira e mantê-la viva.[...] Sempre me proibi - na medida do possível,
é claro, e tão "radical" ou inflexível quanto de ser uma desconstrução- de ferir ou condenar à
morte. É sempre reafirmando a herança que se pode evitar essa condenação à morte. Inclusive
no momento em que - e é a outra vertente da dupla injunção - essa mesma herança ordena,
para salvar a vida (em seu tempo finito), que se reinterprete, critique, desloque, isto é que se
intervenha ativamente para que se tenha lugar uma transformação digna desse nome: para que
alguma coisa aconteça, um acontecimento, da história, do imprevisível por-vir. (p I2- I3- grifos do
original)

Rodrigues (2008) explica a perspectiva desconstrutiva no gesto duplo derridiano de inversão e deslocamento: trazer à tona o recalcado, mas não apenas para invertê-lo, sob pena de criar novas dualidades, mas incitando o deslocamento que elimina a inversão, o que remete a própria dissolução de pares binários que se instituem entre o ser e não ser: verdade/não verdade, fora/dentro, phoné/escrita, abalando as noções de origem e verdade, desfazendo a polarização ao lançá-las no terreno do indecidível. 
É a leitura derridiana que recupero na problematização do signo. Ao dizer que a avaliação ou os resultados dela são tomados como signos de qualidade remeto a noção de signo como determinada, um signo de, referindo-se a um dado de realidade ou, em outros termos, a presença plena. $\mathrm{O}$ signo, no conceito saussuriano, é a união entre imagem acústica/significante e conceito/significado. O signo, nessa formulação, se dá na totalização de um fora - o significante, a exterioridade da escritura (estrita e derivada) e o dentro - o significado, e a busca por uma relação natural entre fora e dentro, entre significante e significado, entre imagem e realidade.

Derrida inverte o privilégio dado ao significado, a relação fora/dentro, na problematização da escritura como imagem, observando como "a representação ata-se ao que representa, de modo que se fala como se escreve, pensa-se como se o representado não fosse mais que a sombra ou o reflexo do representante"(DERRIDA, 20 I la, p.44) e nesse jogo de representação, o ponto de origem já não se torna possível de detectar. E nisso o autor, na análise apurada que faz, investe na discussão da submissão da escrita à fala, operando na leitura dos determinismo postos - na discussão da escrita como imagem de uma realidade em si, mas que o significante não o é em si, uma vez que a palavra-pensamento já é conceito.

A partir dessa inversão que Derrida desloca a discussão, remetendo a própria tese saussuriana de arbitrariedade do signo - que a relação entre determinado significante e determinado significado é arbitrária, ou seja, instituída, o que contesta a ideia de escritura como exterioridade, uma vez que a explicação dessa como imagem, como representação natural da realidade é rejeitada. Nessa esteira, o que se inquire é a garantia da presença, da verdade, da realidade a ser acessada pela representação que a ela é naturalmente ligada.

É preciso pensar a escritura como ao mesmo tempo mais exterior à fala, não sendo sua imagem ou seu símbolo e, mais interior à fala que já é em si mesma uma escritura. Antes mesmo de ser ligado à incisão, à gravura, ao desenho ou à letra, a um significante remetendo, em geral, a um significante por ele significado, o conceito de grafia implica, como possibilidade comum a todos os sistemas de significação, a instância do rastro instituído. (DERRIDA, 20 l la, p.56)

A leitura desconstrutiva que Derrida faz do signo - sem abandonar a metafísica para abalar a metafísica (DERRIDA, 20 I lb) - implica na compreensão da ausência da verdade transcendental, uma vez que não há "em si", ou seja, um significado próprio, mas um jogo de diferenciações, ausência-presença, é sempre uma cadeia de remetimentos que não se deixa aprisionar por um presente simples; é descontinuidade que abala uma lógica linear de tempo e abala a noção de signo em sua totalidade. Não há fora e dentro, mas o fora-dentro implicado, borrado, um fora que está dentro, é origem sem origem ... Há rastros, jogo de diferenças numa relação presença/ausência que não é aprisionada nos limites de representação metafísica oposicional, mas é o outro -alteridade que a mobiliza e que reativa o jogo que movimenta a significação. 
Recorrer a leitura desconstrutiva para formular a defesa que busco desenvolver - a impossibilidade da tomada da avaliação como (ou pela) qualidade - se baseia na discussão que o autor faz na leitura do signo.

Se com Derrida é possível quebrar a linha que conecta de forma direta signo como imagem, como acesso à realidade, ao violar o pacto verticalizado entre significado e significante, isso põe em cheque as noções de transparência e presença: o que se acessa não o é em absoluto, mas efeito de realidade. Essa problemática pode ser examinada à luz da proposição de Bhabha (200 I) que discute como esse efeito de realidade produz o que chama de transparência discursiva e funciona aí também como efeito de autoridade. Fazendo o uso na ideia de transparência, o autor recorre a metáfora da transparência no sentido fotográfico - nesse, ela também é negativa - para ressaltar o efeito de ambivalência do reconhecimento, na dupla visão inscrita pela transparência - "o campo do "verdadeiro" emerge como signo visível de autoridade apenas após a divisão regulatória e deslocadora do verdadeiro e falso" (BHABHA, 200I, p. I60)

Ao desenvolver a discussão nos termos de ambivalência no lugar de presença plena, realidade acessada e reconhecida como tal, há um efeito de incerteza que permite questionar: signo como "presença vazia"? (BHABHA, 200I, p.164). A discussão que o autor faz sublinha a potência do híbrido como perturbador das imagens/presenças de autoridade que se dão com base no reconhecimento.

Ao pôr em diálogo as ideias dos autores, é possível pensar que o estranhamento/deslocamento põe em cheque a retomada de uma origem, essa impossível - o que há são rastros. Na quebra de binarismos e essencialismos, os rastros não asseguram verdades, mas são apostas sem garantia.

Se a ideia de signo alude a espelho da realidade por ele refletida, passível de objetificação, a noção de rastros nos lança em bifurcações, cruzamentos, disjunções que produzem significações provisórias que, longe de estabelecerem fundamentos originários, mantém aberto o jogo da significação - abertura que não implica em relativismo ou nillismo, mas os fechamentos - porque há fechamento - são precários, contingentes e podem ser sempre outros, dada a impossibilidade de precisão de origem/fundamento/centro.

Como rastro, não se trata de presença ou ausência, mas de presença e ausência, na explicação de Haddock-Lobo (2008, p. I I I), "[ ... com esta quase-lógica do rastro, este "indecidível” seria a possibilidade de articulação entre o vivo e o não-vivo, entre o sensível e a idealidade, entre o "mundo" e o "vivido", ou seja, a possibilidade de articular". A partir dessas proposições, o pensamento derridiano impede a totalização; ao nos afastar da lógica mimética do signo, nos leva ao desassossego da articulação ambivalente, entre sedimentação e deslocamento significativo. Esse entendimento afasta-se do essencialismo, da linearidade e continuísmo para nos lançar em movimentos discursivos/iterativos, assim, a significação não está garantida. 


\section{4 À GUISA DE CONCLUSÃO...}

A partir do exercício de leitura proposto é possível tensionar o sentido das avaliações que, mais que constatações de uma realidade dada, exigem interpretação, tomando de empréstimo a formulação de Bhabha (20 I I) acerca da interpretação da obra de arte, como intermediação enquanto intervenção. Assim, a luta pela significação da avaliação como processo disjuntivo questiona a presença do ser.

Essa inflexão põe em suspenso não só o sentido de avaliação bem como o que qualidade. Investir nessa perspectiva sem garantias, sem reconhecimento, mas como acontecimento pode possibilitar a emergência de outras possibilidades para pensar a avaliação como entre-lugar de negociação (BHABHA, 200 I), que não significa a negação da avaliação. O que se defende é que a ausência de fundamento, origem e verdade, na discussão aqui proposta, suspende a ideia de tomada de decisão entre verdade/qualidade e não verdade/não qualidade, para além disso, a decisão se dá no terreno do indecidível que a não impede, ao contrário, exige decisão e aí responsabilidade.

Alinhar essas ideias à problematização da avaliação desestabiliza a origem de sentido de qualidade acessado via resultado e a garantia que esse seja mantido como referente, como verdade, tal como é percebido na relação estabelecida nas políticas curriculares contemporâneas. A avaliação é tomada como capaz de, ao mesmo tempo, incitar e dar garantias de qualidade, coisificada no contexto de produções curriculares que também fazem do currículo objeto, com funcionamento determinado e controlado pelas avaliações. $\bigcirc$ que defendo é abrir mão do cálculo que esquadrinha e fixa, da pretensão de controle que a avaliação traz e nisso a redução do currículo a previsibilidade apriorística que atrofia seus próprios sentidos. Trata-se da abertura à incerteza (CUNHA, 2016), sem temer a indecidibilidade, mas pensando-a possibilidade de decisão responsável. Assim, pensar da avaliação constatativa à uma avaliação performática e no atravessamento dessas, emergir como acontecimento.

\section{REFERÊNCIAS}

AÇÃO EDUCATIVA; UNICEF; PNUD; INEp-MEC. Indicadores de Qualidade da Educação. São Paulo: Ação Educativa, 2004.

BHABHA, Homi. O Bazar global e o clube dos cavalheiros ingleses. Rio de Janeiro: Rocco, 20 I I

BHABHA, Homi. O local de cultura. Belo Horizonte: UFMG, 200।

BRASIL. DECRETO No 9.432, DE 29 DE JUNHO DE 20 I8. Regulamenta a Política Nacional de Avaliação e Exames da Educação Básica. Diário Oficial da União. Brasília/DF: seção I, ano I55, no. I25, p. I

BRASIL/MEC. Base Nacional Comum Curricular. Brasília, MEC, SEB, 2017. 
BRASIL/MEC. Orientações para as etapas de Monitoramento e Avaliação da formação continuada para os novos currículos - Anexo. IN: Guia de implementação da Base Nacional Comum Curricular orientações para o processo de implementação da BNCC. Disponível em:

https://implementacaobncc.com.br/recursos/?etapa $=4$. Acesso em mar/2020.

BRASIL/MEC. Pacto nacional pela alfabetização na idade certa - Caderno de Apresentação: MEC, SEB, 2013

BRASIL/MEC. PNA - Política Nacional de Alfabetização/Secretaria de Alfabetização (Caderno). - Brasília: MEC, SEALF, 2019

BRASIL/MEC/CNE. Parecer CNE/CP 22/2019 - Diretrizes Curriculares Nacionais para a Formação Inicial de Professores para a Educação Básica e Base Nacional Comum para a Formação Inicial de Professores da Educação Básica (BNC-Formação). Brasília: CNE, 7/I I/2019. Disponível em: http://portal.mec.gov.br/acessibilidade-sp-9406746 |4/3337/ -cne-conselho-nacional-deeducacao/7434I-parecer-cp-2019

CUNHA, Érika Virgílio Rodrigues da. Conexão entre currículo e avaliação como ficção de controle da identidade. IN: FRANGELLA, Rita de Cássia (org.). Currículo, formação e avaliação - redes de pesquisa em negociação. Curitiba: CRV, 2016.

DERRIDA, Jacques. A escritura e a diferença. São Paulo: Perspectiva, 20 I lb

DERRIDA, Jacques. Gramatologia. São Paulo: Perspectiva, 20 I la

DERRIDA, Jacques; ROUDINESCO, Elizabeth. De que amanhã: diálogos. Rio de Janeiro, Jorge Zahar Ed, 2004.

DIAZ-BARRIGA, A. De laevaluación individual a laevaluación social-integrada: lainstitucion educativa, suunidad. In: BARRIGA, A. D. Docencia y evaluación em la Reforma Educativa (Coord.). 2003

FRANGELLA, Rita de Cássia e CAMPOS, Maria Cristina. Autoavaliação institucional: outros sentidos de avaliação (im)possíveis? Estudos Avaliação Educacional, São Paulo, v. 30, n. 74, p. 558-587, maio/ago. 2019.

FRANGELLA, Rita de Cássia Prazeres; MENDES, Juliana Camila Barbosa. "O que é o bom resultado?" Indagando o sentido da avaliação e suas articulações curriculares. Ensaio: avaliação e política pública em Educação . 2018, vol.26, n.99, pp.296-315.

HADDOCK-LOBO, Rafael. Derrida e o labirinto das inscrições. Porto Alegra: ZOUK, 2008.

IBGE. Pesquisa Nacional por Amostra de Domicílios Contínua: Educação:20 I 8

LAVAL, Christian. Governar pela crise democrática. Revista Cult, edição 219, 2017.

MACEDO, Elizabeth. A noção de crise e a legitimação de discursos curriculares. Currículo sem Fronteiras, v. 13, n. 3, p. 436-450, set./dez. 2013

RODRIGUES, Carla. Mulher, verdade, indecidibilidade. IN: DUQUE-ESTRADA, Paulo Cesar. Espectros de Derrida. Rio de Janeiro: NAU Editora, p. 91-120, 2008.

TAUBMAN, Peter. Teaching by numbers: Deconstructing the discourse of standards and accountability in education. New York: Routlegde, 2009. 


\section{COMO CITAR ESSE ARTIGO}

\section{Associação Brasileira de Normas Técnicas (ABNT)}

FRANGELLA, Rita de Cássia Prazeres. Avaliação como signo de qualidade: problematizando as

(in)definições nas produções curriculares. Debates em Educação, Maceió, v. 12, p. 558-57I, 2020. ISSN 2175-6600. Disponível em: https://www.seer.ufal.br/index.php/debateseducacao/article/view/I 002I. Acesso em: dd mmm. aaaa.

\section{American Psychological Association (APA)}

Frangella, R. (2020). Avaliação como signo de qualidade: problematizando as (in)definições nas produções curriculares. Debates em Educação, 12(Esp), 558-57l. doi: https://doi.org/l0.28998/21756600.2020vI2nEspp558-57I 